\title{
A JUDICIALIZAÇÃO DOS TRATAMENTOS CONTRA A DROGADIÇÃO NO ESTADO DO ESPÍRITO SANTO: UMA ANÁLISE ECONÔMICA SOBRE O DISPENDIO DOS RECURSOS UTILIZADOS
}

Felipe Dutra Asensi ${ }^{1}$

Luciano Motta Nunes Lopes ${ }^{2}$

Diego Machado Monnerat ${ }^{3}$

\section{Resumo}

O trabalho objetiva empreender uma análise econômica sobre os gastos que a judicialização dos tratamentos contra a toxicodependência causam nas despesas do Fundo Estadual de Saúde do Espírito Santo (FES). Trata-se de pesquisa documental, exploratória, retrospectiva e descritiva com abordagem quali-quantitativa. Foram utilizados resultados dos estudos sobre os fenômenos da judicialização direta e indireta da saúde, fornecidos pelo Portal da Transparência do Governo do Estado do Espírito Santo e as informações diretamente prestadas pelo FES. Segundo constatou-se em pesquisa realizada pela $1^{\text {a }}$ Vara da Infância e da Juventude da Comarca de Cachoeiro de Itapemirim/ES, os tratamentos contra a drogadição responderam pela maior parte dos pedidos demandados judicialmente no ano de 2013. Em nível estadual, observou-se que a compra de leitos para tratamentos de dependentes químicos e transtornos mentais, realizadas por força de determinação judicial, responderam por 49,36\% do total de pagamentos dessa rubrica no exercício de 2015. Concluiu-se que os problemas relacionados ao uso e abuso de drogas constituem grave problema de saúde pública, ocasionando profundos impactos sociais e econômicos, o que sugere medidas urgentes por parte dos gestores públicos no sentido de se elaborar e implementar políticas de saúde mental eficazes e especificamente direcionadas ao

\footnotetext{
${ }^{1}$ Pós-Doutor em Direito pela Universidade do Estado do Rio de Janeiro (UERJ). Membro do Comitê Consultivo Nacional da Biblioteca Virtual de Saúde (BVS-Integralidade). Membro Titular da Red Iberoamericana de Derecho Sanitario. Membro do Conselho Curador do PenseSUS (Fiocruz). Membro da Asociación Latinoamericana de Sociología (ALAS). Professor Adjunto da UERJ/UCP/USU. E-mail: felipedml@yahoo.com.br

${ }^{2}$ Mestre em Direito pelo Programa de Pós-graduação "Justiça Administrativa" da Universidade Federal Fluminense (UFF). Professor on line (mediador) da Escola Nacional de Socioeducação (ENS), do Centro de Estudos Avançados de Governo e Administração Pública (CEAG) e da Universidade Nacional de Brasília (UNB).E-mail: Imnlopes@hotmail.com

${ }^{3}$ Mestre em Direito da Universidade Católica de Petrópolis. Professor nos cursos de Pós-Graduação em Gestão Jurídica da Saúde e Direito Sanitário da Faculdade Unyleya. E-mail: monneratdm@gmail.com
} 
tratamento contra a toxicodependência.

Palavras-chave: Direito à saúde. Judicialização da saúde. Tratamento contra a drogadição. Impactos econômicos. Espírito Santo.

\section{INTRODUÇÃO}

Em face do constante desafio inerente ao financiamento dos serviços públicos de saúde, alguns gestores têm procurado desenvolver um maior planejamento técnico de seus gastos e ações, objetivando atender à cobertura universal e isonômica dos usuários do Sistema Único de Saúde (SUS).

Entretanto, ao proferir decisões em questões relacionadas à saúde, o Poder Judiciário interfere administrativamente na gestão do SUS, uma vez que Administração Pública vê-se obrigada a realocar recursos inicialmente destinados a programas coletivos para atender demandas privadas e individuais.

Noutra senda, em virtude da ineficiência do Estado em implementar algumas políticas públicas, como é o caso do tratamento contra a drogadição, a judicialização cristaliza-se como o principal mecanismo capaz de proteger e de tornar efetivo o direito fundamental à saúde.

É sobre essa premissa que o presente artigo encontra-se ancorado, isto é, identificar e analisar os reflexos financeiros que a judicialização dos tratamentos contra a drogadição causam na rubrica do Fundo Estadual da Saúde (FES) do Espírito Santo, ao mesmo tempo em que busca correlacionar o fenômeno identificado em nível estadual com os resultados advindos da pesquisa sobre a judicialização direta e indireta da saúde, efetivada na $1^{\text {a }}$ Vara Especializada da Infância e da Juventude da Comarca de Cachoeiro de Itapemirim/ES.

\section{ESTRATÉGIA METODOLÓGICA}

O estudo empregou técnicas de pesquisa documental, exploratória, retrospectiva e descritiva com abordagem quali-quantitativa. Os dados analisados foram extraídos da pesquisa sobre a judicialização direta e indireta da saúde; da base de dados eletrônicos do Portal da Transparência do Governo do Estado do Espírito Santo; e das informações fornecidas diretamente pelo Fundo Estadual de Saúde (FES), as quais foram solicitadas judicialmente pela juíza titular da supracitada Vara da Infância e da Juventude. 


\section{A JUDICIALIZAÇÃO DA SAÚDE}

Com o advento da Carta Magna de 1988, a saúde foi elevada ao status de direito de cidadania, tonandose uma prestação positiva a ser realizada pelo Estado. Todavia, em razão das imensas dificuldades enfrentadas pelo Poder Público, sobretudo no que concerne ao subfinanciamento crônico de um sistema de saúde eminentemente universal, a Administração Pública não tem logrado êxito em atender às diretrizes constitucionais e legais.

Essa realidade que assola grande parte da população é a principal responsável pela judicialização da saúde, fenômeno através do qual demandas relacionadas ao direito à saúde são levados ao crivo do Poder Judiciário para resolução definitiva.

De acordo com Marques (MARQUES, 2008, pp. 65-70), a participação do Judiciário nessa seara pode ser considerada uma atividade positiva, tendo em vista que seria capaz de reduzir as omissões e as violações de direitos cometidas pelo próprio Estado contra seus cidadãos. Nesse sentido, representa um progresso em relação à efetividade do exercício da cidadania da população brasileira. Por outro lado, salienta a autora:

significa um ponto de tensão perante os elaboradores e executores da política no Brasil, que passam a atender um número cada vez maior de ordens judiciais, garantindo as mais diversas prestações do Estado (MARQUES, 2008, pp. 65-70).

De fato, a judicialização da saúde pode gerar profundas consequências em âmbito jurídico, social e econômico, inclusive promovendo em alguns casos o remanejamento de recursos. Assim, verbas que foram inicialmente destinadas ao financiamento de programas e serviços públicos de saúde podem ser realocadas para atenderem a demandas particulares e isoladas.

Esse desvio legal de dinheiro público tem causado enormes prejuízos ao SUS, razão pela qual se torna imperioso realizar uma profunda reflexão crítica sobre o papel que vem sendo desempenhado pelos operadores do direito, sobretudo os magistrados. As decisões judiciais que vêm sendo emanadas não podem ignorar as políticas e os programas públicos de saúde que já se encontram em plena vigência. Logo, devem ser proferidas de forma racional e em estrita observância às leis e não de forma individualizada a todos aqueles que buscam o Poder Judiciário para satisfazer seus interesses pessoais (SILVA, 2008. p.587-588).

Nesse mesmo sentido Perlingeiro (2013) alertou-nos que, embora essas pretensões judiciais sejam, em regra, individuais, elas são suportadas por recursos financeiros afetos aos próprios serviços públicos de saúde em geral. Desse modo, o autor defende a adoção de mecanismos que propiciem maior dimensão e potencialidade à tutela jurisdicional, de forma a assegurar isonomia e equidade entre todos os beneficiários do SUS:

[...] como uma medida jurisdicional individual dessa natureza atinge uma diversidade de usuários daquele mesmo serviço público, significa que a satisfação da pretensão judicial correspondente deve ser condicionada a uma reestruturação prévia da autoridade administrativa quanto à distribuição dos recursos disponíveis às sucessivas demandas que lhes são apresentadas extrajudicialmente. 
È por tal razão que a justicialidade dos direitos aos cuidados da saúde reclama a judicialização prévia ou mesmo, quando necessário, simultânea do direito procedimental equivalente (PERLINGEIRO, 2013, p. 528$529)$.

Ao entregar a prestação da tutela jurisdicional no âmbito da saúde pública, o magistrado pode influenciar diretamente na atividade estatal, considerando que pode haver a destinação de recursos destinados à coletividade para uma única pessoa. Entrementes, em sentido diametralmente oposto, assegurará à parte que teve seu direito negado, cerceado ou violado pela Administração Pública, a oportunidade de ter o seu direito fundamental à saúde materializado.

Durante pesquisa empírica realizada junto à $1^{a}$ Vara Especializada da Infância e da Juventude de Cachoeiro de Itapemirim/ES, Lopes, Asensi e Silva Junior identificaram duas formas de se judicializar a saúde, que denominaram "judicialização direta e indireta da saúde"(2017, p. 295). No que tange à judicialização direta, os autores elucidam que:

Usualmente, a judicialização da saúde ocorre de forma direta, ordinária em seu nascedouro, posto que a materialização do direito à saúde é o objeto principal da ação ajuizada. Nela, o fluxograma de ações evidencia que essa forma de judicialização da saúde pode operar-se de duas maneiras: a) quando o usuário percorre a via administrativa previamente estabelecida e não consegue obter seu tratamento; b) no momento em que o usuário decide procurar diretamente a Justiça, sem passar pela via administrativa. No caso da opção "a", o fluxograma de ações parte do usuário que necessita de cuidado em saúde e segue a via administrativa pré-determinada. Ao procurar a Unidade Básica de Saúde (UBS) de seu território e ser devidamente encaminhado para a Central de Regulação Municipal (CRM) para agendamentos, o usuário não logra êxito em receber o tratamento de que necessita, geralmente em razão da negativa de oferta ou demora no atendimento. Irresignado, procura o Poder Judiciário como alternativa viável para a resolução de seu problema. Devidamente patrocinado pelo Ministério Público, Defensoria Pública ou advogado particular, o usuário ajuíza uma ação na qual o pleito requerido é o fornecimento de insumo médico ou tratamento que precisa. Ato contínuo, o juiz defere ou indefere os termos da inicial e a ação segue a regular tramitação de um contencioso judicial. Na hipótese "b", o fluxograma de ações também se inicia a partir do usuário que carece de assistência à saúde. Porém, ele decide acionar o Poder Judiciário diretamente, sem passar pelas vias ordinárias administrativas. Essa conduta normalmente ocorre em razão do prévio conhecimento da letargia ou da negativa de atendimento por parte da Administração Pública (LOPES; ASENSI; SILVAJUNIOR, 2017, p. 295-296).

Já em relação à judicialização indireta, esclarecem que:

$\mathrm{Na}$ judicialização indireta da saúde, a petição que propõe a aplicação de medidas protetivas na área da saúde é interposta de forma superveniente ou incidental, levantada no bojo de um processo que, a priori, não fora iniciado por questões relativas à saúde. Seu fluxograma de ações demonstra que a violação do direito à saúde de crianças e adolescentes não fazia parte da narrativa constante da peça inicial. Essa lesão foi identificada após os autos se encontrarem em pleno andamento, o que ensejou, de forma transversa, uma atuação específica do Poder Judiciário e do Ministério Público para restabelecerem o pleno exercício do direito negado. Assim, em dada fase processual, após procederem-se averiguações in loco para se aquilatar situações de risco ou de vulnerabilidade em face de crianças e adolescentes, vislumbrou-se pela equipe técnica interprofissional a necessidade de intervenção do Poder 
Judiciário, cujas considerações são devidamente relatadas ao juízo. Em seguida, o representante do Ministério Público analisa o parecer, sugestão ou laudo que foi acostado aos autos. Se o parquet entender pertinente e apropriado ao caso, apresenta petição superveniente à peça vestibular na qual propõe a aplicação de "medidas protetivas incidentais". A utilização deste instrumento processual visa a garantir o acesso de crianças e adolescentes aos serviços públicos de saúde que lhes foram negados ou cerceados pelo Estado. Nesse ínterim, com base no art. 98 c/c art. 101 do ECRIAD, o juiz, em decisão interlocutória com efeitos de antecipação da tutela, aplica as medidas de proteção sugeridas, compelindo à Administração Pública a fornecer o medicamento ou tratamento à criança ou adolescente. Após a intimação da parte demandada (Poder Público), acaso haja resistência, o processo seguirá a tramitação normal de um contencioso judicial, com estrita observância a todas as garantias legais e processuais vigentes, em especial, ampla defesa, contraditório e devido processo legal. Se não houver contestação e o tratamento for efetivamente disponibilizado, os autos são extintos por resolução do mérito (LOPES; ASENSI; SILVA JUNIOR, 2017, p. 296-297).

Com base na citada pesquisa, infere-se que tanto a judicialização direta quanto a indireta da saúde configuram-se em importantes mecanismos jurídicos de garantia de acesso às ações e políticas públicas de saúde, na medida em que garante àquelas crianças e adolescentes que tiveram seu direito fundamental à saúde violado a expectativa de vê-lo materializado.

\section{A JUDICIALIZAÇÃO DA SAÚDE NO ESTADO DO ESPÍRITO SANTO}

Os tópicos dispostos a seguir serão expostos levando-se em consideração os elementos, situações, práticas e instituições que se relacionam com o fenômeno da judicialização da saúde no estado do Espírito Santo. Pari passu, a análise dos marcos temporais identificará a evolução dos gastos públicos e os desafios que precisam ser suplantados pelo governo.

\section{Fundo Estadual de Saúde}

No Estado do Espírito Santo, todos os pagamentos destinados a subsidiar o cuidado em saúde são realizados por intermédio do Fundo Estadual de Saúde (FES), inclusive aqueles oriundos de determinações judiciais.

Instituído nos termos do art. $1^{\text {o }}$ da Lei no 4.873 de 10 de janeiro de 1994, o FES tem por finalidade precípua "criar condições financeiras e de gerência dos recursos destinados a custear o desenvolvimento das ações e serviços de saúde, executados ou coordenados pela Secretaria de Estado da Saúde" (ESPÍRITO SANTO, 1994, p. 1).

A criação desse fundo operou-se em razão do disposto no art. 4º da Lei Federal no 8.142 , de 28 de dezembro de 1990, o qual estabeleceu que os Estados, assim como os municípios e o Distrito Federal, deveriam 
contar com um Fundo de Saúde, dentre outros requisitos, para receberem repasses de verbas provenientes do Fundo Nacional de Saúde (FNS).

Os dados apurados na pesquisa comprovaram que o incremento no processo de judicialização da saúde influenciou diretamente na sustentabilidade do FES. Este fato pode ser devidamente averiguado a partir da exposição dos dados relativos ao período de 2011 à 2014, no qual se identificou aumento exponencial de ações judiciais na área da saúde no território capixaba: ${ }^{4}$
a) 2011 - 2.453;
b) $2014-4.618$

A evolução dos números acima destacados possibilita uma projeção estatística com base nos dados coletados para o ano de 2015 (3.378 de janeiro à agosto). Assim sendo, estimou-se que:

c) Em 2015 haveria um quantitativo aproximado de 5.067 processos.

A compilação dos dados expostos pode ser vislumbrada no Gráfico 1.

Gráfico 1 - Quantitativo de processos ajuizados em face do Estado do Espírito Santo

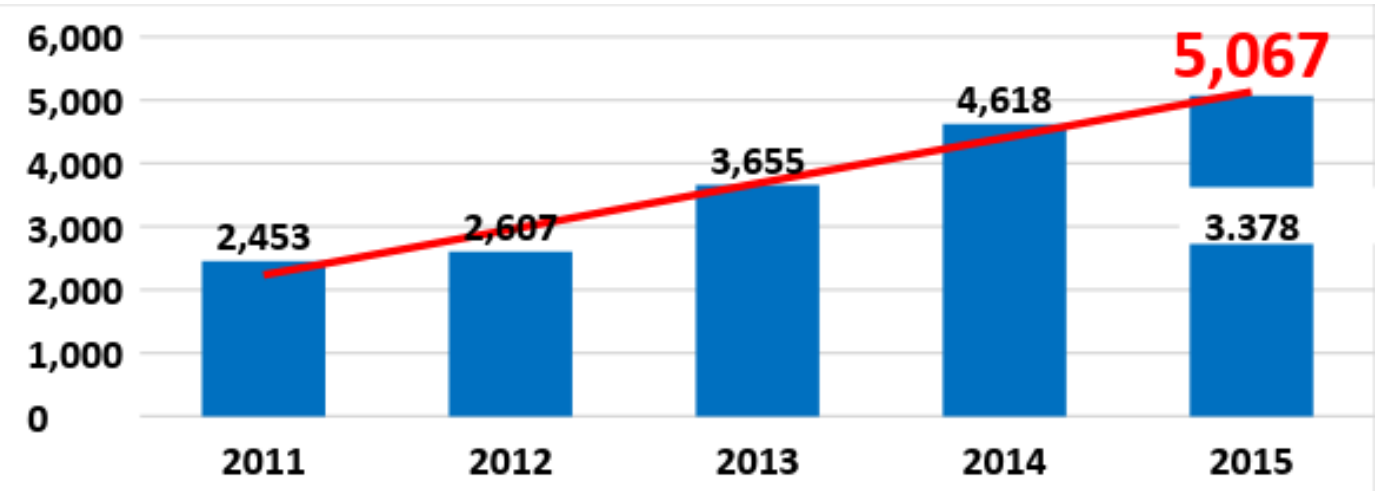

Obs.: Os dados relativos ao ano de 2015 (5.067) referem-se a uma previsão estatística, haja vista que os números inicialmente coletados (3.378) apenas dizem respeito ao quantitativo apurado no período de janeiro a agosto.

Fonte: Governo do Estado do Espírito Santo. Disponível em: <http://slideplayer.com.br/slide/8659157/>. Acesso em $24 / 07 / 2016$

d) Ainda em relação ao ano de 2015, segundo dados fornecidos pelo portal da transparência, ${ }^{5}$ o total de receitas apuradas pelo Governo do Estado do Espírito Santo foi de R\$ 14.656.876.993,89, ao passo que as

\footnotetext{
${ }^{4}$ Informações prestadas pelo então Secretário de Estado da Saúde do Espírito Santo, Ricardo de Oliveira, durante o $3^{\circ}$ Congresso Brasileiro Médico e Jurídico "Impacto das Ordens Judiciais no Orçamento Público e o Direito à Saúde", realizado em Vitória/ES, no ano de 2015, as quais também foram utilizadas para compor o gráfico 3 . Disponível em http://slideplayer.com.br/slide/8659157/.Acesso em 24/07/2016.

${ }^{5}$ http://www.transparencia.es.gov.br.
} 
despesas liquidadas somaram $\mathrm{R} \$ 12.049 .711 .848,17$. Dentre os valores referentes aos gastos, observa-se que os pagamentos realizados por intermédio do FES alcançaram a cifra de R $\$ 1.949 .317 .070$, 04, o que corresponde a 16,18\% do total do quadro de detalhamento de despesas pagas por órgão, conforme o Gráfico 2.

Gráfico 2 - Detalhamento de despesas por órgão - Período consultado: 01/01/2015 a 31/01/2015.

Total pago: R\$ 12.049.711.848,17.
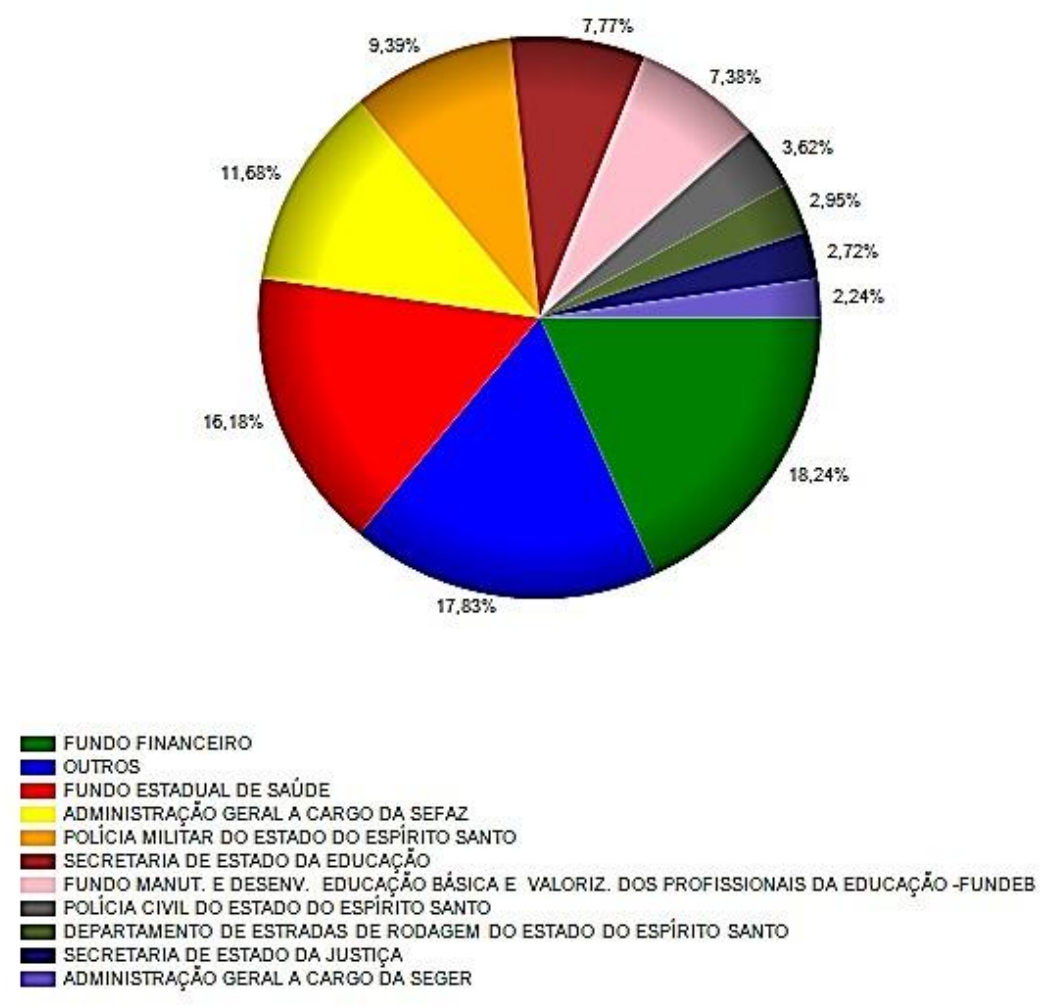

Fonte: Portal da Transparência. em: <http://www.transparencia.es.gov.br/graficos/Despesas/Relatorios.aspx?nome=RelatorioDespesasOrgaoUGPago\&ano=2015\& dataInicio=0101\&dataFim $=3112>$. Acesso em 12/07/2016.

O gráfico 3 diz respeito ao impacto financeiro que as decisões judiciais causam nos recursos provenientes do FES. Ele foi construído com base nas informações divulgadas pela Secretaria de Estado da Saúde e nos dados fornecidos pelo Portal da Transparência do Governo do Estado do Espírito Santo. 
Gráfico 3 - Impacto financeiro das decisões judiciais nos recursos do FES - Elemento de despesa "Sentenças Judiciais".

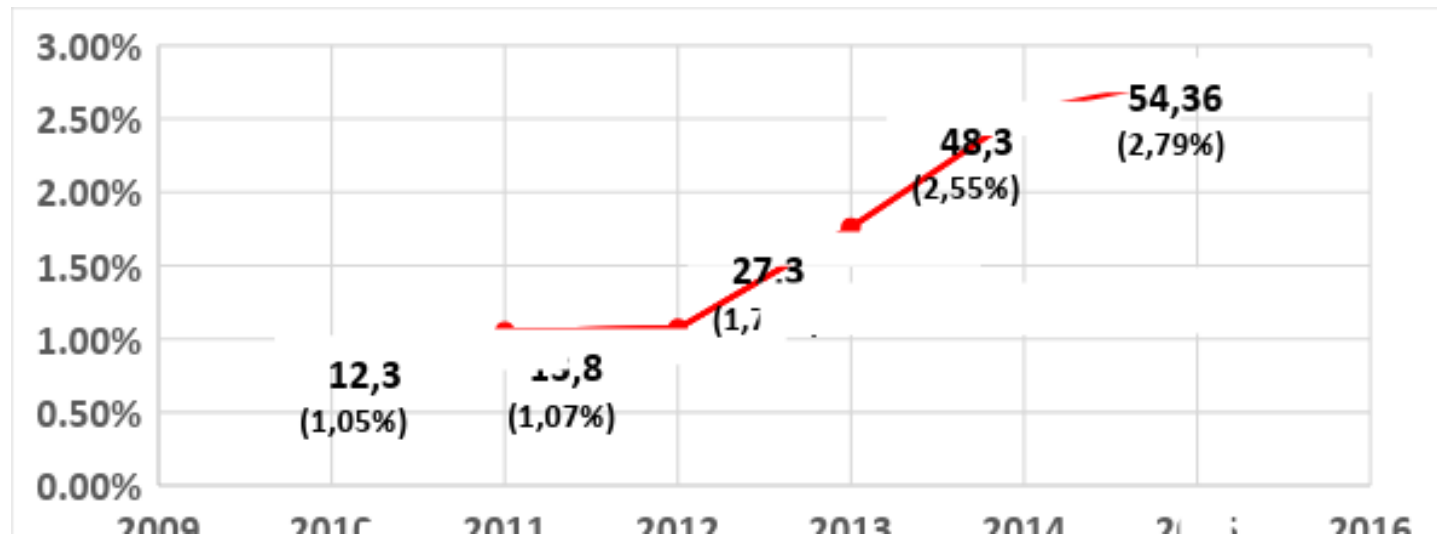

Obs. 1: Os percentuais informados no eixo vertical referem-se ao as despesas liquidadas por força de mandado judicial frente ao total de despesas realizadas pelo Fundo Estadual de Saúde.

Obs. 2: Os valores das despesas informados na linha ascendente estão na escala de milhões.

Fonte 1: Governo do Estado do Espírito Santo. Disponível em: <http://slideplayer.com.br/slide/8659157/>. Acesso em $24 / 07 / 2016$

Fonte 2: Portal da transparência. <http://www.transparencia.es.gov.br/graficos/Despesas/Relatorios.aspx?nome=RelatorioDespesasOrgaoUGPago\&ano=2015\& dataInicio $=0101 \&$ dataFim $=3112>$. Acesso em 24/07/2016

2011 e 2012: a judicialização da saúde permaneceu estacionada no Espírito Santo, representando pouco mais de $1 \%$ dos gastos realizadas anualmente pelo FES.

2013: observa-se uma relativa evolução desse elemento de despesas, cujo percentual alcançou 1,76\% dos dispêndios do FES.

2015: o total dos gastos realizados por intermédio do fundo atingiu o patamar de 2,79\%, o que corresponde à quantia de $\mathrm{R} \$ 54.363 .791,07$.

Portanto, as constantes decisões judiciais que tem obrigado o Estado do Espírito Santo a fornecer tratamento ou insumo médico de forma individualizada estão em escala ascendente, causando profundo desequilíbrio econômico nos recursos do FES. Dentre as demandas de saúde que figuram no mérito das decisões, o tratamento contra a drogadição assume uma posição de destaque, sendo este o objetivo central do presente trabalho. 


\section{Tratamento contra drogadição}

Em virtude da ineficiência da Administração Pública em fornecer aos dependentes químicos programas e ações específicas e eficazes contra a drogadição, a judicialização da saúde no estado do Espírito Santo tem ganhado força, conforme se observa a partir da análise dos seguintes dados quantitativos:

Em 2013, o total de despesas liquidadas com a compra de leitos para tratamento de dependentes químicos e transtornos mentais, realizada por força de determinação judicial, foi de R \$ 12.741.927,23;

Já em 2015, de acordo com números fornecidos pelo FES, ${ }^{6}$ constata-se que o quantum acima mencionado saltou para R \$ 43.064.574,82.

O estudo desses números evidencia um aumento de $237,97 \%$ do total de recursos que tiveram que ser redirecionados do FES para atenderem a demandas relativas à saúde mental. Os Gráficos abaixo dão um panorama mais didático do exposto:

Gráfico 4 - Despesas Liquidadas nos Exercícios de 2013/2014/2015 com a compra de Leitos para tratamento de Transtornos Mentais/Dependência Química por força de mandado Judicial.

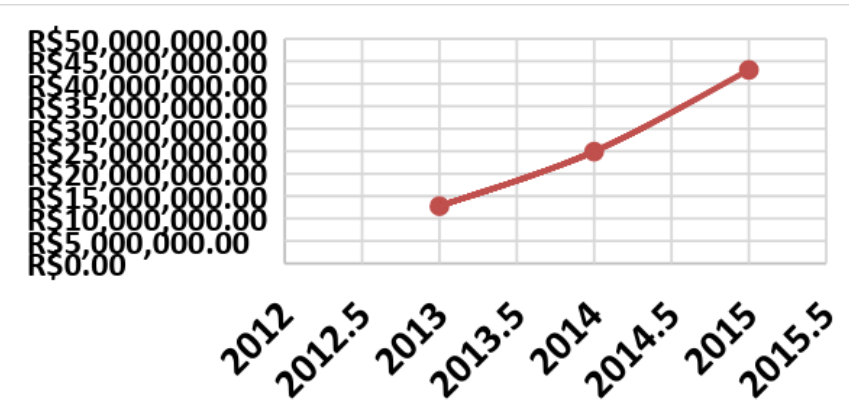

Fonte: Governo do Estado do Espírito Santo

Ainda em 2015, a compra de leitos para tratamento de dependência química e transtornos mentais já respondia por 49,36\% do total de pagamentos realizados por força de determinação judicial pelo Fundo Estadual de Saúde, o que caracteriza notória concentração de pedidos na área de saúde mental, conforme Gráfico 5 abaixo destacado. 
Gráfico 5 - Detalhamento de despesas realizadas no exercício de 2015 com a compra de leitos para tratamento contra a drogadição e transtornos mentais - Elemento de despesa "sentenças judiciais" -

Período consultado: 01/01/2015 a 31/01/2015.

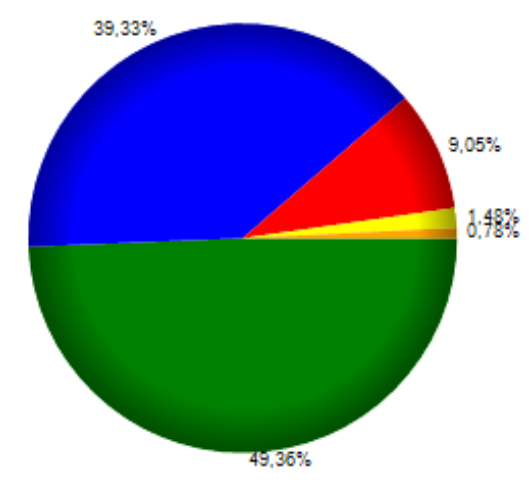

Fonte:

Portal

da

Transparência.

http://www.transparencia.es.gov.br/graficos/Despesas/Relatorios.aspx?nome=RelatorioDespesasOrgaoUGPag $\mathrm{o} \& \mathrm{ano}=2015 \&$ dataInicio $=0101 \&$ dataFim $=3112$. Acesso em 12/07/2016.

Os subsídios fornecidos pelos gráficos 5 e 6 trazem à lume uma importante característica da realocação dos recursos do FES com a compra de leitos para tratamento contra a dependência química: a suplementação do poder público, via organizações privadas, para o fornecimento de assistência à saúde.

Nesse sentido, observa-se que o maior valor liquidado na citada planilha encaminhada pelo FES pertence ao "Instituto Assistencial de Atenção ao Uso de Drogas Nova Aliança". A instituição, cuja sede encontra-se localizada em Piúma, cidade litorânea do sul do Estado do Espírito Santo, presta serviços exclusivos de atenção a pessoas com transtornos mentais e comportamentais devido ao uso, abuso ou dependência de substancias psicoativas.

No que tange aos pagamentos realizados ao Instituto Nova Aliança, identificou-se os seguintes gastos liquidados:

$2013-\mathrm{R} \$ 2.944 .125,00$.

\footnotetext{
${ }^{6}{ }^{3}$ Números encaminhados via planilha à $1^{\text {a }}$ Vara Especializada da Infância e da Juventude da Comarca de Cachoeiro de Itapemirim/ES, via email institucional.
} 
$2015-\mathrm{R} \$ 10.859 .420,00$.

Os números constantes no gráfico 6 demonstram um incremento da ordem de 268,85\% nos pagamentos realizados ao Instituto Nova Aliança com a compra de leitos. Durante esse período (2013 a 2015), as despesas quitadas somaram R $\$ 18.829 .280,00$.

Gráfico 6 - Total de Despesas liquidadas nos Exercícios de 2013/2014/2015 junto ao "Instituto Assistencial de Atenção ao Uso de Drogas Nova Aliança"

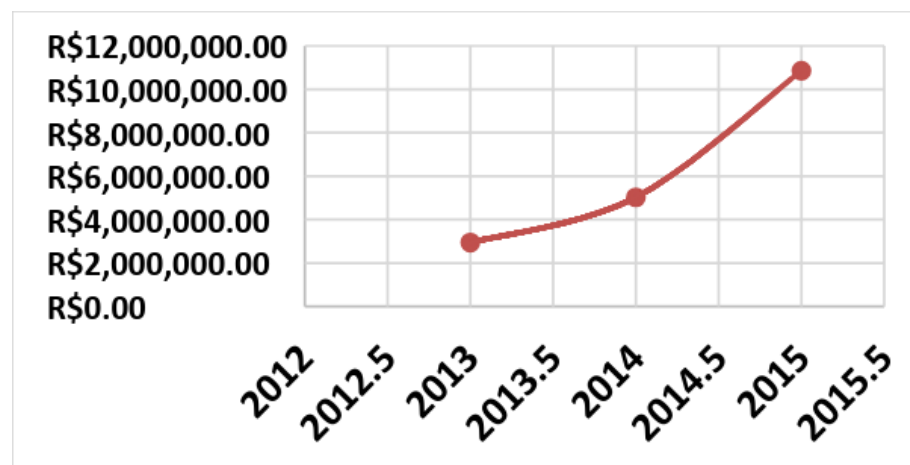

Fonte: Governo do Estado do Espírito Santo

Em que pese os dados fornecidos tratarem simultaneamente da compra de leitos para tratamento contra a drogadição e transtornos mentais é evidente que as questões relacionadas ao uso ou abuso de drogas respondem pela ampla maioria das demandas. Isto porque grande parte das instituições contratadas dedicam-se exclusivamente ao tratamento de transtornos mentais relacionados à toxicodependência.

Os números apontam que a judicialização do cuidado em saúde mental no Estado do Espírito Santo encontra-se em franca expansão, haja vista o crescimento das despesas realizadas por força de decisões judiciais.

Essa constatação não passou ao largo da Secretaria Estadual da Saúde do Espírito Santo (SESA) que sugeriu a implementação de atividades que apontassem soluções concretas para as demandas. Simultaneamente, decidiu avaliar as instituições que patrocinavam essas demandas específicas, priorizando ações com objetivos táticos, operacionais e estratégicos. Ao se identificar a alta concentração de pedidos de internação para dependentes químicos em algumas varas e comarcas, propôs-se realizar um 'detalhamento da situação', visando a construir um fluxo razoável de atendimento aos usuários, tendo em vista que o Estado tem o dever de estabelecer uma política pública de resposta mais efetiva aos cidadãos interessados. Por fim, dentre as medidas sugeridas, destacaram-se a qualificação dos profissionais, o direcionamento dos fluxos, a adoção de um termo de 
referência para o credenciamento e a aquisição de internações como soluções possíveis viáveis frente à problemática suscitada (DANTAS et al., 2015, p. 5).

\section{Judicialização dos tratamentos contra a drogadição na $1^{\text {a }}$ Vara Especializada da Infância e da Juventude de Cachoeiro de Itapemirim/ES}

A pesquisa realizada junto à $1^{\text {a }}$ Vara Especializada da Infância e da Juventude da Comarca de Cachoeiro de Itapemirim/ES, identificou e analisou os principais elementos e características que permeiam os fenômenos da judicialização direta e indireta da saúde, merecendo destaque os resultados obtidos quanto ao polo passivo demandado e os tratamentos e insumos médicos que foram pleiteados.

Em se tratando de polo passivo demandado, verificou-se que o estado do Espírito Santo figurou como réu em $89,20 \%$ dos processos (66) nos quais se evidenciou a judicialização direta da saúde ao passo que o município de Cachoeiro de Itapemirim foi requerido em apenas 5,40\% dos casos (4), conforme o Gráfico 7.

Gráfico 7 - Polo passivo demandado na Judicialização Direta

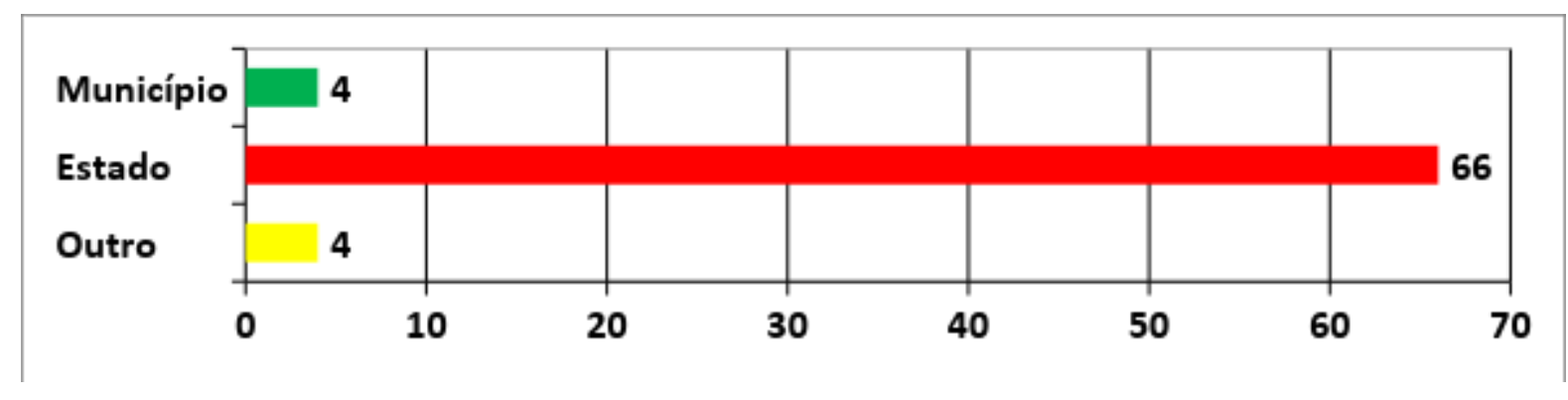

Fonte: dos autores.

Já em relação à judicialização indireta da saúde, constatou-se que o Estado capixaba foi requerido em 92,10\% dos pedidos supervenientes interpostos (35). Em sentido oposto, o município de Cachoeiro de Itapemirim foi demandado em apenas 2,63\% das ações indiretas, possuindo apenas 1 pedido, conforme demonstrado no Gráfico 8. 
Gráfico 8 - Polo passivo demandado na Judicialização Indireta

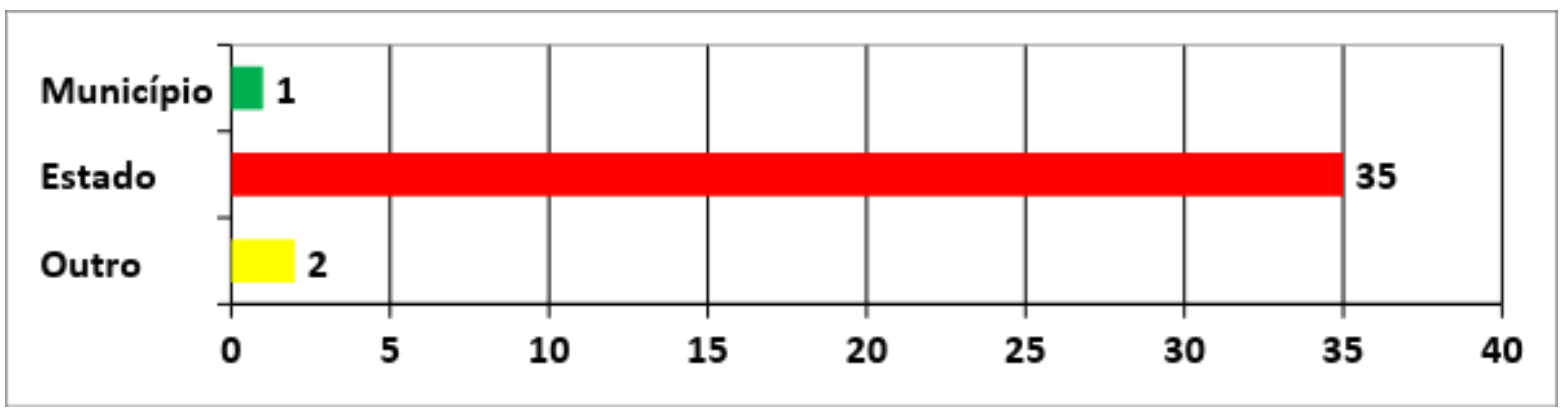

Fonte: Lopes, Asensi e Silva Júnior (2016).

A análise destes dados evidencia, portanto, que os índices relacionados ao polo passivo demandado na judicialização direta da saúde encontram-se bem próximos e guardam simetria frente aos resultados verificados na judicialização indireta.

A identificação de um elevado percentual de ações contra o Estado do Espírito Santo apurado neste trabalho se aproxima com a pesquisa "Diagnóstico das Ações Judiciais Direcionadas à Secretaria de Estado da Saúde do Espírito Santo" (ESPÍRITO SANTO, 2010, p. 19), em que se constatou que a Comarca de Cachoeiro de Itapemirim/ES, quando em análise comparativa populacional frente aos demais municípios, apresentava alto percentual de ações judiciais em face do Estado. O documento relata, ainda, a preocupação dos gestores frente à anomalia diagnosticada e destaca a premente necessidade de se desenvolver estratégias de intervenção neste município.

Por fim, a pesquisa constatou que $43,5 \%$ das decisões judiciais que emanaram das varas de Cachoeiro de Itapemirim/ES compeliram o estado ao fornecimento de medicamentos da atenção básica, ou seja, que são da obrigatoriedade do município. Desta forma, restou identificada a inobservância dos magistrados aos princípios da responsabilidade tripartite da organização do sistema.

Nessa mesma esteira de raciocínio, em análise preliminar, infere-se que as reiteradas decisões, originárias ou supervenientes, que obrigaram o Estado do Espírito Santo a fornecer tratamento contra a drogadição não seguiram as diretrizes adotadas pela Política Nacional Sobre Drogas - PNAD, de 2011 - a qual se norteia pelo princípio da responsabilidade compartilhada entre todos os entes e níveis da federação.

Decerto, as decisões emanadas em primeira instância carecem de maior rigor legislativo e de profundo conhecimento sobre políticas públicas de saúde, sobretudo por envolverem questões eminentemente interdisciplinares e intersetoriais, evitando-se sobrecarregar um ente federativo em detrimento de outro.

No que concerne aos tratamentos e insumos pleiteados via judicialização direta perante a 1a Vara da Infância e da Juventude de Cachoeiro de Itapemirim/ES no ano de 2013, o estudo revelou que o maior 
percentual de pedidos ajuizados diz respeito aos tratamentos contra a drogadição, malgrado os indicadores apurados tenham identificado relativa pulverização desses elementos. Nesse sentido, aquilatou-se que as consultas especializadas que tinham como objetivo indicar o melhor tratamento contra a toxicodependência (12,50\%) e as internações $(8,75 \%)$ responderam por $21,25 \%$ do total de insumos e tratamentos pleiteados originariamente. Os alimentos/leites (12,5\%), exames (10\%), medicamentos (7,5\%) e cirurgias (13,75\%) também responderam por significativos índices desse quesito (TABELA 1).

Tabela 1 - Insumos e tratamentos pleiteados na Judicialização Direta

\begin{tabular}{|c|c|c|}
\hline Insumos e Tratamentos & $\begin{array}{c}\text { Quantitat } \\
\text { ivo }\end{array}$ & $\begin{array}{c}\text { Perce } \\
\text { ntual }\end{array}$ \\
\hline Alimentos, Leites e assemelhados & 10 & $12,5 \%$ \\
\hline Cadeiras de Rodas, Órteses, Próteses e Aparelhos Auditivos & 03 & $3,75 \%$ \\
\hline Consulta Especializada: Psiquiatria ou Psicologia & 05 & $6,25 \%$ \\
\hline $\begin{array}{c}\text { Consulta Especializada: Psiquiatria ou Psicologia, Objetivando } \\
\text { Indicar o Melhor Tratamento Contra Drogadição }\end{array}$ & 10 & $12,5 \%$ \\
\hline Outras Consultas Médicas Especializadas & 2 & $2,5 \%$ \\
\hline Exames & 8 & $10 \%$ \\
\hline Fraldas & 6 & $7,5 \%$ \\
\hline Lentes Especiais & 1 & $1,25 \%$ \\
\hline Medicamentos & 6 & $7,5 \%$ \\
\hline Procedimentos cirúrgicos & 11 & 13,75 \\
\hline Tratamentos Especializados & 3 & $3,75 \%$ \\
\hline Tratamento Especializado Therasuit & 5 & $6,25 \%$ \\
\hline Tratamento Odontológico & 1 & $1,25 \%$ \\
\hline Tratamento Contra Drogadição em Nível de Internação & 7 & $8,75 \%$ \\
\hline Outros & 2 & $2,5 \%$ \\
\hline Total & 80 & $100 \%$ \\
\hline
\end{tabular}

Fonte: dos autores.

No âmbito da judicialização indireta da saúde (TABELA2), a pesquisa revelou que 34\% dos pedidos interpostos referiam-se à consulta especializada com a finalidade de indicar o melhor tratamento contra a dependência química e 18,2\% versavam sobre tratamento contra a drogadição em nível de internação. Assim sendo, conclui-se que a maior parte dos pedidos demandados de forma superveniente também estiveram relacionados a tratamentos contra a toxicodependência, eis que somaram $52,2 \%$ do total dos tratamentos e insumos pleiteados. 
Tabela 2 - Insumos e tratamentos pleiteados e que foram deferidos na Judicialização Indireta

\begin{tabular}{|c|c|c|}
\hline Insumos e Tratamentos & $\begin{array}{c}\text { Quantitat } \\
\text { ivo }\end{array}$ & $\begin{array}{c}\text { Perce } \\
\text { ntual }\end{array}$ \\
\hline Consulta Médica Especializada: Neuropediatria & 07 & $15,9 \%$ \\
\hline Consulta Médica Especializada: Oftalmologia & 01 & $2,3 \%$ \\
\hline Consulta Especializada: Psiquiatria ou Psicologia & 11 & $25 \%$ \\
\hline $\begin{array}{c}\text { Consulta Especializada: Psiquiatria ou Psicologia, Objetivando } \\
\text { Indicar o Melhor Tratamento Contra Drogadição }\end{array}$ & 15 & $34 \%$ \\
\hline $\begin{array}{c}\text { Consulta Especializada: Psiquiatria ou Psicologia, Objetivando } \\
\text { Indicar o Melhor Tratamento Contra Drogadição para os Genitores ou } \\
\text { Responsáveis }\end{array}$ & 1 & $2,3 \%$ \\
\hline Encaminhamento da Família ao Programa Estratégia Saúde da \\
Família
\end{tabular}

Fonte: Lopes, Asensi e Silva Junior (2016).

Os dados apurados nas tabelas 1 e 2 demonstram, de forma inequívoca, que o cuidado em saúde mental, especificamente direcionado ao tratamento contra a drogadição, tem sido o mais importante gargalo da saúde infanto-juvenil que fora judicializado de forma direta (ordinária) ou indireta (superveniente).

Segundo extrai-se de uma outra planilha fornecida pelo FES, ${ }^{7}$ as demandas concernentes a tratamentos contra a drogadição, em nível de internação de crianças e adolescentes, ajuizadas no ano de 2013, perante a 1ª Vara da Infância e da Juventude da Comarca de Cachoeiro de Itapemirim/ES, somaram R \$ 403.955,00. Esses valores equivalem a uma média de $\mathrm{R} \$ 36.723,18$ por processo, tendo sido computados com base em decisões judiciais cujos tratamentos foram efetivamente realizados e pagos pelo Estado do Espírito Santo. Contudo, os valores informados encontram-se incompletos, uma vez que dizem respeito a apenas 11 de um total de 16 ações que foram ajuizadas. Dentre os casos relativos a valores que não foram lançados na sobredita planilha, identificou-se situações nas quais ainda não houve o pagamento do tratamento pelo Estado (2), ausência de internação (1) e processos não localizados (2).

Hodiernamente, as questões relacionadas ao uso e abuso de drogas constituem grave problema de saúde pública, especialmente se envolverem crianças e adolescentes, devendo ser tratadas com urgência e tecnicidade pelos órgãos de gestão sanitária e pelo Sistema de Garantia de Direitos - SGD.

Os resultados obtidos apontam para uma problemática que é inerente à grande parte dos municípios brasileiros e não somente Cachoeiro de Itapemirim/ES: a ausência de políticas públicas específicas e direcionadas

\footnotetext{
${ }^{7}$ Planilha encaminhada pelo Fundo Estadual de Saúde do Estado do Espírito Santo à 1a Vara da Infância e da Juventude de Cachoeiro de Itapemirim/ES, via email institucional.
} 
ao tratamento da drogadição para crianças e adolescentes.

Em recente pesquisa realizada, Leal, Santos e Jesus (LEAL, SANTOS, JESUS, 2014), identificaram que em todo o Estado do Espírito Santo existia somente um CAPS-AD infanto-juvenil, estabelecido em Vitória, capital. Essa constatação vai de encontro à diretriz 2.2.5 da Política Nacional sobre Drogas (PNAD), formulada pela Secretaria Nacional de Políticas Sobre Drogas (SENAD), a qual estabelece que as diversas modalidades de tratamento devem atender às demandas específicas de alguns grupos, em especial, crianças e adolescentes (BRASIL, 2011, p. 18).

Corroborando com a assertiva acima descrita, Raupp e Sapiro (RAUPP; SAPIRO, 2009, p. 446) aduzem que o encaminhamento de crianças e adolescentes para realizarem tratamentos contra a toxicodependência em espaços destinados a adultos não é apropriada e encontra-se em assimetria frente às principais políticas públicas desenvolvidas pelo setor e pelo próprio Estatuto da Criança e do Adolescente. Ao final, sentenciam que:

[...] o tratamento da drogadição para crianças e adolescentes destaca-se como uma 'questão problema', devido à escassez de locais adequados e de profissionais capacitados para atender às demandas singulares desse público[...] (RAUPP; SAPIRO, 2009, p. 446)

Portanto, a análise desses números indica notória fragilidade das políticas públicas no âmbito da saúde mental desenvolvidas pelo Estado do Espírito Santo e município de Cachoeiro de Itapemirim. Ao mesmo tempo, evidencia a ausência de ações e programas públicos de saúde contra a drogadição especificamente direcionada ao público infanto-juvenil, consubstanciada no número limitado de CAPS, leitos para internação e de profissionais capacitados na recuperação de usuários e dependentes químicos.

\section{CONSIDERAÇÕES FINAIS}

Os resultados apurados na presente pesquisa demonstraram que a judicialização da saúde no Estado do Espírito Santo encontra-se em plena fase evolutiva. Somente no período compreendido entre 2011 a 2014, o número de processos ajuizados anualmente saltou de 2.453 para 4.618, o que revela um aumento da ordem de $88,25 \%$ no quantitativo de ações que foram impetradas em face do estado.

Essas demandas produzem sérios impactos econômicos, causando efeitos nocivos nos recursos do FES, os quais são utilizados para subsidiar o cuidado à saúde da população em geral. Segundo informações prestadas pelo Governo do Estado do Espírito Santo, os gastos realizados para o cumprimento das chamadas "sentenças judiciais" chegou a consumir 2,79\% do total do ordenamento de despesas liquidadas pelo FES no período de 2015, alcançando a cifra de $\mathrm{R} \$ 54.363 .791,07$.

Dentre as principais características processuais encontradas na pesquisa, merece destaque a alta concentração de pedidos que versavam sobre a compra de leitos para tratamentos contra a drogadição e 
transtornos mentais, responsáveis por 49,36\% do total de pagamentos realizados pelo governo capixaba em razão de mandado judicial no ano de 2015.

Os elementos identificados pelo trabalho em nível estadual guardam simetria e expressam verossimilhança frente aos dados apontados pela recente pesquisa sobre a judicialização direta e indireta da saúde, realizada na 1ª Vara Especializada da Infância e da Juventude da Comarca de Cachoeiro de Itapemirim/ES. Nela, aquilatou-se que a ampla maioria dos pedidos ajuizados de forma direta (originária) ou indireta (superveniente) também se referiam a tratamentos contra dependência química.

Diante dos dados apurados e da identificação dos gargalos judicializados, constata-se que as questões relacionadas à toxicodependência têm atingido importante camada da população adulta e infanto-juvenil, configurando-se em grave problema de saúde pública a ser enfrentada de forma institucional, técnica, dialógica e interdisciplinar pelos gestores sanitários, profissionais da área de saúde e pela sociedade civil organizada.

Destarte, as possíveis soluções apontadas para a problemática caminham no sentido de envidar esforços objetivando a implementação de políticas públicas de saúde, especificamente direcionadas ao tratamento contra a drogadição de crianças e adolescentes, uma vez que elas praticamente inexistem nos municípios capixabas. Pari passu, deve-se aprimorar os programas contra a toxicodependência para o público adulto que já estão em pleno funcionamento, adotando-se metas relacionadas à qualificação dos profissionais de saúde, direcionamento dos fluxos, adoção de um termo de referência para o credenciamento e a aquisição de internações. Decerto, tais ações seriam de bom alvitre e garantiriam ao cidadão acesso de qualidade a serviços públicos de tratamento contra a dependência química.

\title{
THE JUDICIALIZATION OF TREATMENTS AGAINST DRUG ADDICTION IN THE STATE OF ESPÍRITO SANTO: AN ECONOMIC ANALYSIS ON THE DISPENSING OF RESOURCES USED
}

\begin{abstract}
The work aims to undertake an economic analysis of the expenditures that the judicialization of treatments against drug addiction cause in the expenditure of the State Health Fund of the Espírito Santo (FES). This is documentary research, exploratory, retrospective and descriptive with qualitative and quantitative approach. It uses the results of direct and indirect health justice phenomena, provided by the Transparency Portal of the Government of the State of Espírito Santo and as information directly provided by the FES. According to it was found in a recent survey conducted by the 1st Court of Children and Youth Cachoeiro County of Itapemirim / ES, treatment against drug addiction accounted for most of the defendants in court order in 2013. At the state level, it was observed the purchase of beds for drug addicts treatment and mental disorders, conducted by judicial determination, accounted for $49.36 \%$ of all payments under this heading in the 2015 exercise. It appears that the problems related to drug use and abuse are major public health problem, causing deep social and economic impacts, suggesting urgent action by public officials in order to design and implement mental health policies
\end{abstract}


effective and specifically targeted treatment against addiction.

Keywords: Right to health. Judicialization of health. Treatment against drug addiction. Economic impacts. Espírito Santo.

\section{REFERÊNCIAS BIBLIOGRÁFICAS}

BRASIL. Lei 8.142/1990, de 28 de dezembro de 1990. Dispõe sobre a participação da comunidade na gestão do Sistema Único de Saúde (SUS \} e sobre as transferências intergovernamentais de recursos financeiros na área da saúde e dá outras providências. Diário Oficial da União. Brasília, 31 dez. 1990. Disponível em: < http://www.planalto.gov.br/ccivil_03/leis/L8142.htm>. Acesso em: 24 de jul. 2016.

Ministério da Justiça. Secretaria Nacional sobre Drogas - SENAD. Legislação e Políticas Públicas sobre Drogas no Brasil. Brasília, DF, 2011. Disponível em: < http://www.justica.gov.br/central-de-conteudo/politicassobre-drogas/cartilhas-politicas-sobre-drogas/201 llegislacaopoliticaspublicas.pdf $>$. Acesso em: 05 jul. 2016.

DANTAS, Anselmo; MAGESTE, Rosane; MATTOS, Victor W.; ESTEVES, Carolina B. O fenômeno da judicialização da saúde como estratégia de acesso aos serviços de saúde. Coleção para entender a gestão do SUS Direito à saúde. Conass. $1^{\text {a }}$ ed. 2015. Disponível em: <http://www.conass.org.br/biblioteca/pdf/colecao2015/CONASS-DIREITO_A_SAUDE-ART_19.pdf>. Acesso em: 26 jul. 2016.

ESPÍRITO SANTO. Lei no 4.873/1994, de 10 de janeiro de 1994. Dispõe sobre a criação do Fundo Estadual de Saúde - FES - e dá outras providências. Diário Oficial. Vitória, ES, 14 jan. 1994. Disponível em: <http://www.al.es.gov.br/antigo_portal_ales/images/leis/html/LO\%204873.html>. Acesso em:09 jul. 2016.

Secretaria de Estado da Saúde. Diagnóstico das ações judiciais direcionadas à Secretaria de Estado da Saúde do estado do Espírito Santo. Vitória, 2010. Disponível em: <http://www.escoladegoverno.pr.gov.br/arquivos/File/Material_\%20CONSAD/paineis_III_congresso_cons ad/painel_9/diagnostico_das_acoes_judiciais_direcionadas_a_secretaria_de_estado_da_saude_do_espirit o_santo.pdf $>$. Acesso em: 14 jul. 2016.

LEAL, Fabíola Xavier; SANTOS, Caroline Christine Moreira dos; JESUS, Renata Santos de. Políticas de atenção às questões relacionadas ao consumo de álcool e outras drogas no Espírito Santo. 78 f. Relatório de pesquisa Centro de Ciências Jurídicas e Econômicas - Departamento de Serviço Social - Universidade Federal do Espírito Santo. Vitória, 2014.

LOPES, Luciano Motta Nunes; ASENSI, Felipe Dutra; SILVA JÚNIOR, Aluísio Gomes da. A judicialização Indireta da Saúde: um estudo de caso sobre a experiência da 1a Vara Especializada da Infância e da Juventude da Comarca de Cachoeiro de Itapemirim. Revista Direito \& Práxis. Rio de Janeiro, v. 8, n. 1, p. 285-320, 2017. Disponível em: http://www.scielo.br/scielo.php?pid=S217989662017000100285\&script=sci_abstract\&tlng=pt. Acesso em 31 jan. 2018.

MARQUES, Silvia Badim. Judicialização do direito à saúde. Revista de Direito Sanitário. São Paulo, v. 9, n. 2, p. 6572, 2008. Disponível em: <http://www.revistas.usp.br/rdisan/article/view/13117/14920 >. Acesso em 19 out. 2015. 
PERLINGEIRO, Ricardo. Novas perspectivas para a judicialização da saúde no Brasil. Revista Scientia Iurídica, Braga/Portugal, Tomo LXII. 2013, n. 333, p. 519-539, Dez. 2013.

RAUPP, Luciane; SAPIRO, Clary Milnitsky. Adolescência, drogadição e políticas públicas: recortes no contemporâneo. Estudos de Psicologia. Campinas, 2009, outubro-dezembro, p. 445-454. Disponível em: $<$ http://www.scielo.br/pdf/estpsi/v26n4/05.pdf>. Acesso em 05 jul. 2015.

SILVA, Virgílio Afonso da. O Judiciário e as políticas públicas: entre transformação social e obstáculo à realização dos direitos sociais. In: Cláudio Pereira de Souza Neto \& Daniel Sarmento, Direitos sociais: fundamentação, judicialização e direitos sociais em espécies, Rio de Janeiro: Lumen Juris, 2008. P. 587-599.

Trabalho enviado em 16 de março de 2018

Aceito em 05 de jultho de 2018 